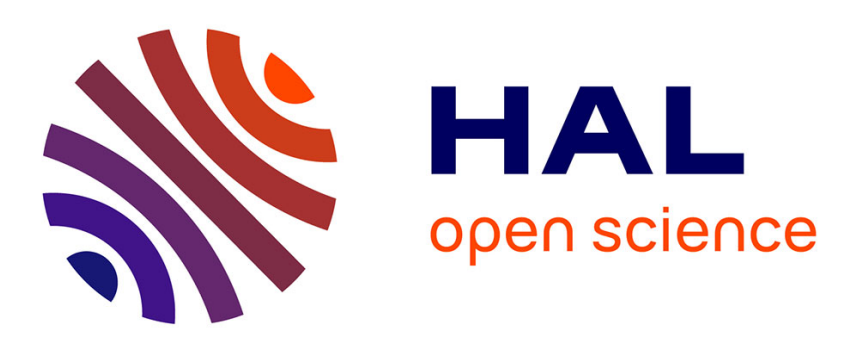

\title{
Scheduling Optimization of Smart Homes Based on Demand Response
}

\author{
Jiawei Zhu, Fabrice Lauri, Abderrafiaa Koukam, Vincent Hilaire
}

\section{To cite this version:}

Jiawei Zhu, Fabrice Lauri, Abderrafiaa Koukam, Vincent Hilaire. Scheduling Optimization of Smart Homes Based on Demand Response. 11th IFIP International Conference on Artificial Intelligence Applications and Innovations (AIAI 2015), Sep 2015, Bayonne, France. pp.223-236, 10.1007/978-3319-23868-5_16. hal-01385358

\section{HAL Id: hal-01385358 \\ https://inria.hal.science/hal-01385358}

Submitted on 21 Oct 2016

HAL is a multi-disciplinary open access archive for the deposit and dissemination of scientific research documents, whether they are published or not. The documents may come from teaching and research institutions in France or abroad, or from public or private research centers.
L'archive ouverte pluridisciplinaire HAL, est destinée au dépôt et à la diffusion de documents scientifiques de niveau recherche, publiés ou non, émanant des établissements d'enseignement et de recherche français ou étrangers, des laboratoires publics ou privés.

\section{(c)(1)}

Distributed under a Creative Commons Attribution| 4.0 International License 


\title{
Scheduling Optimization of Smart Homes based on Demand Response
}

\author{
Jiawei Zhu, Fabrice Lauri, Abderrafiaa Koukam, and Vincent Hilaire \\ IRTES-SET, UTBM, 90010 Belfort cedex, France \\ (jiawei.zhu, fabrice.lauri, abder.koukam, vincent.hilaire)@utbm.fr
}

\begin{abstract}
Demand response can potentially lead to economic and environmental advantages, but non-coordinated scheduling and operation of controllable devices in a set of smart homes will make peak rebounds at periods with lower electricity prices happen, which may damage the power grid, cause unforeseen disasters, and reduce the global profit. In this work, we advocate the use of a metaheuristic algorithm based on Cooperative Particle Swarm Optimization to optimize scheduling and operation of time-shiftable and power-shiftable devices in a set of smart homes of a district. By employing this method, user comfort is guaranteed, electricity cost is reduced and total load on the main grid is flattened so that the global energy efficiency is improved.
\end{abstract}

Keywords: smart grid, smart home, demand response, particle swarm optimization, energy

\section{Introduction}

Corresponding to the increasing demands for environment, comfort, and energy, smart home has become an active research topic. Smart home, also known as automated home or intelligent home, is the residential extension of smart building. It is an automation system that incorporates a diverse of home appliances with ubiquitous computing, networking, and controlling abilities, forming an "Internet of Things", to provide better home life service and experience to residents $[1,2]$. A smart home system does not simply turn devices on and off. It can also monitor their working states and detect the environment to make better decisions. The two most important aspects in smart homes that should be considered carefully are comfort level and energy efficiency.

Generally, different occupants have different definitions of comfort level and at the same time certain extents of uncomfortableness are tolerated for them. Therefore it allows the dynamic balance of comfort obtained and energy consumption in smart homes. When we talk about the energy efficiency, it represents on one hand the efficiency of generating units, and on the other hand the energy cost paid by occupants. In this field, smart homes can be treated as integral additions to smart grid, which is a modernized electrical grid using information and communication technologies to improve the efficiency, reliability, economics, 
and sustainability of the production and distribution of electricity [3]. Communication between smart homes and the smart grid allows flexible home appliances shifting working time or adjusting working power during on-peak periods to balance the usage of electricity. In this sense, demand response is one of the key energy management strategy adopted both by the smart grid and smart homes. It refers to changes in electric usage by end-use customers from their normal consumption patterns in response to changes in the price of electricity over time, and helps to reduce peak demand, therefore tempering the need to operate high-cost and high-emission generating units as well as cutting down residents' electricity bills [4].

In recent years, great efforts have been made to activate demand response potentials of residential customers and incorporate it in smart home systems that optimize the scheduling and operating status of relative intelligent appliances. In [5], a real-time price-based demand response management model for residential appliances is proposed. This management model is embedded into smart meters, employing scenario-based stochastic optimization and robust optimization approaches to determine the optimal operation considering future electricity price uncertainties. Authors of [6] propose a stochastic energy consumption scheduling algorithm, which takes the time-varying pricing information, distributed renewable generation, and the customer-defined target trip rate as inputs, and generates an operation schedule to minimize the monetary expense. A decisionsupport tool based on particle swarm optimization is presented in [7] to help residential consumers optimize their acquisition of electrical energy services. With this approach, the minimization of monetary expense and the maximization of user comfort are balanced based on user-defined monetary benefits for electric services.

However, all of them only think about the scheduling of electric devices in a single resident case, that is to say the smart home with these approaches merely considers to optimize its profit by reducing the usage of flexible appliances during peak-load hours or deferring them to low price periods. In general, it ignores the states of its neighbours. As indicated in [8], it shows that when the load management of a set of homes work selfishly, new peak-loads will occur during lower electricity price periods and it is called peak rebounds[9]. This accentuates the necessity of an effective global demand response management scheme to ensure the coordination among them. In [10], a multi-agent based approach is developed to minimize different smart homes' electricity bills in line with the grid's goal to flatten the total demand curve. Other work that considers to maximize various users' profits while avoiding severe peak-load rebounds can be found in $[9,11,12]$. But in almost all of them, user comfort is not considered adequately. For example, deferring the operation of washing machine until the midnight should be avoided, for the noise will disturb the sleeping residents.

In this work, we propose a metaheuristic algorithm based on Cooperative Particle Swarm Optimization (CPSO) to optimize scheduling and operation of time-shiftable and power-shiftable devices in a set of smart homes of a district. By employing this algorithm, not only user comfort is guaranteed and energy 
consumption is reduced in individual smart home, but also peak rebounds are avoided on the power grid so that the global energy efficiency is improved. The contribution of this work is threefold: firstly, an objective function that considers dissatisfaction and energy cost of individual home and electricity variances on the grid is proposed, meanwhile typical household appliances are categorized and modelled; secondly, due to the problem involves a lot of variables, a metaheuristic algorithm based on CPSO is developed to solve it; thirdly, by conducting experiments in three cases, we demonstrate the applicability and usefulness of the proposed method.

The rest of this paper is organized as follows. Section 2 mathematically formulates the problem. Section 3 presents the proposed method in detail. Experimental results and analysis are given in section 4 . Finally, we conclude in section 5 .

\section{Problem Formulation}

This section intends to present mathematical formulations for the problem we need to solve. The objective function is introduced firstly. Then we divide controllable household appliances into two categories: power-shiftable and time-shiftable respectively, and formulate mathematical models for each of them.

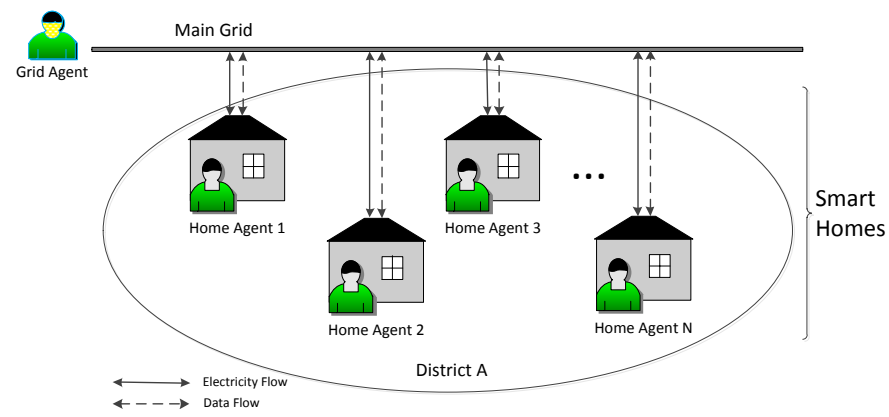

Fig. 1. System Architecture

\subsection{Objective Function}

The system architecture is shown in fig.1. In a District $A$, there are $N$ smart homes connecting to the main grid to exchange data and buy/sell electricity. The Grid Agent and Home Agent are responsible for managing the main grid and each smart home respectively. In a smart home, different electric appliances are operated to work or planed to work in order to satisfy occupants' requirements. 
When they function properly, occupants' comfort can be guaranteed, whereas running defectively or unreasonably can reduce the satisfaction, for example in case of space over or under heating or scheduling a washing machine to work during midnight. Therefore one of the system goals is to minimize the dissatisfaction caused by these appliances in each smart home. Furthermore, demand response enabled by time-varying prices can propel customers to change their consumption patterns for a more economical purpose, such as turning down some devices' working power during on-peak periods and deferring some devices' running time to off-peak periods. Hence, decreasing the household cost of electricity usage should be considered in the system. However, a non-coordinated response of customers for time-varying prices may lead to severe peak rebounds at periods with lower prices. For example, when all $N$ customers in District $A$ prefer to use air-conditioning, washing machine, dish washer, etc. during off-peak time selfishly, the total load on the main grid will turn to be extremely high. This will increase the burden of generating units, do harm to the main grid, and bring unforeseen disasters. Towards flattening the total load profile, the variance of energy consumption on the main grid need to be minimized. Corresponding to these three situations, the objective function of each household $i$ is to minimize the integration of the three sub-objectives, where the dissatisfaction and the cost can be evaluated by its individual home agent while the variance is evaluated by the grid agent based on power scheduling data received from all smart homes in the district, as expressed below:

$$
\min \text { Dissatisfaction }(i)+\alpha \cdot \operatorname{Cost}(i)+\beta \cdot \text { Variance }
$$

where $\alpha$ and $\beta$ are two weight factors. The three sub-objectives are calculated as:

$$
\begin{gathered}
\text { Dissatisfaction }(i)=\sum_{t=1}^{T} \sum_{j=1}^{S}\left[I_{i j}(t) \cdot U_{i j}(t)\right] \\
\text { Cost }(i)=\sum_{t=1}^{T}\left[\rho(t) \cdot \sum_{j=1}^{S} P_{i j}(t)\right] \\
\text { Variance }=\sum_{t=1}^{T}\left[\sum_{i=1}^{N} \sum_{j=1}^{S} P_{i j}(t)-\frac{1}{|T|} \sum_{i=1}^{N} \sum_{t=1}^{T} \sum_{j=1}^{S} P_{i j}(t)\right]^{2}
\end{gathered}
$$

where

$t, T$ index and set of time interval,

$i, N$ index and set of household,

$j, S$ index and set of electric appliance,

$I_{i j}(t)$ binary variable denoting allowable working status of appliance $j$

in household $i$ at time $t$,

$U_{i j}(t)$ dissatisfaction caused by operating appliance $j$

in household $i$ at time $t$,

$\rho(t) \quad$ electricity sale price at time $t$

$P_{i j}(t)$ working power of appliance $j$ in household $i$ at time $t$. 
Household appliances can be divided as fixed devices, which have fixed load profiles such electric oven, refrigerator, TV, etc., and controllable devices including power-shiftable devices and time-shiftable devices, that will be particularly described in the next two subsections.

\subsection{Power-Shiftable Devices}

Power-shiftable devices represent these devices whose working power is changeable to fit variations of environmental status, and at some circumstances they can decrease the power at the range that occupants can accept to reduce load on grid. Two main power-shiftable devices considered in this work are electric space heater and electric water heater.

The dissatisfaction by using the space heater is defined as:

$$
\begin{gathered}
\Delta_{s h}(t)=T_{i n}^{*}(t)-T_{i n}(t) \\
U_{s h}(t)= \begin{cases}\Delta_{s h}(t) \times \epsilon & \text { if } 0<\Delta_{s h}(t)<\zeta \\
\Delta_{s h}(t)^{2} \times 10 & \text { otherwise }\end{cases}
\end{gathered}
$$

where $T_{i n}^{*}(t)$ and $T_{i n}(t)$ are the desired temperature and the actual indoor temperature at time $t$ respectively; $U_{s h}(t)$ is the dissatisfaction caused by using the space heater at time $t ; \epsilon$ is a small scalar number; $\zeta$ is a temperature difference limit that occupants can tolerate. It means the farther away the indoor temperature is from the desired temperature the more dissatisfaction comes, and if the temperature difference is under occupants' tolerance, the dissatisfaction is negligible. According to [13], the discrete time model using one-hour time step for indoor temperature variations is given by

$$
T_{\text {in }}(t+1)=T_{\text {in }}(t) e^{-1 / \tau}+R \cdot P_{\text {sh }}(t) \cdot\left(1-e^{-1 / \tau}\right)+T_{\text {out }}(t) \cdot\left(1-e^{-1 / \tau}\right)
$$

where $R$ is the thermal resistance of the building shell in ${ }^{\circ} \mathrm{C} / \mathrm{kW}, C$ is the heat capacity of indoor air in $k W h /{ }^{\circ} C, \tau=R \cdot C, P_{s h}(t)$ is the working power of the space heater at time $t$, and $T_{\text {out }}(t)$ is the outdoor temperature at time $t$.

The dissatisfaction by using the water heater is defined as:

$$
\begin{gathered}
\Delta_{w h}(t)=T_{h o t}^{*}(t)-T_{h o t}(t) \\
U_{w h}(t)= \begin{cases}\Delta_{w h}(t) \times \theta & \text { if } 0<\Delta_{s h}(t)<\eta \\
\Delta_{w h}(t)^{2} \times 10 & \text { otherwise }\end{cases}
\end{gathered}
$$

where $T_{h o t}^{*}(t)$ and $T_{h o t}(t)$ are the desired hot water temperature and the actual hot water temperature at time $t$ respectively; $U_{w h}(t)$ is the dissatisfaction caused by using the water heater at time $t ; \theta$ is a small scalar number; $\eta$ is a temperature difference limit of hot water that occupants can tolerate.

In modelling water heating, we assume that the storage of hot water is always full, which means the equivalent of cold water enters the storage immediately 
when some hot water is drawn to be used. Hence, based on the heat balance, the temperature of hot water at each hour is calculated from the following equation:

$$
\begin{aligned}
T_{\text {hot }}(t+1)= & \frac{V_{\text {outflow }}(t) \cdot\left(T_{\text {cold }}(t)-T_{\text {hot }}(t)\right)+V_{\text {total }} \cdot T_{\text {hot }}(t)}{V_{\text {total }}} \\
& +\frac{P_{\text {wh }}(t)}{V_{\text {total }} \cdot C_{\text {water }}}
\end{aligned}
$$

where $C_{\text {water }}$ is the specific heat of water in $k W h / L \cdot{ }^{\circ} C, P_{w h}(t)$ is the heating power of the water heater at time $t, V_{\text {total }}$ is the total volume of the hot water storage, $V_{\text {outflow }}(t)$ and $T_{\text {cold }}(t)$ are the volume of hot water drawn to be used and the cold water temperature at time $t$ separately.

\subsection{Time-Shiftable Devices}
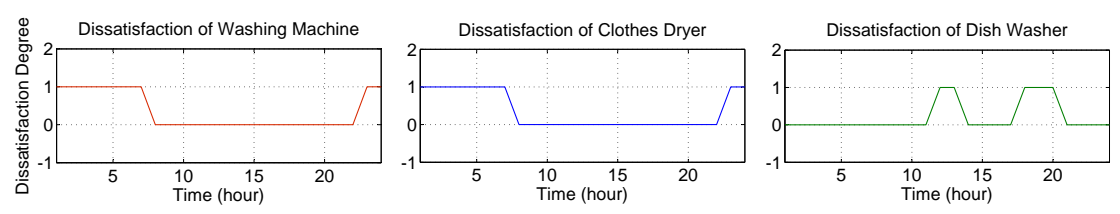

Fig. 2. Dissatisfaction of Time-Shiftable Devices

Time-shiftable devices are these appliances that can shift the power consumption time within a preferred working period and when they start to work they are in a constant power for a certain period. In this work, three timeshiftable appliances are considered: washing machine, clothes dryer, and dish washer. The dissatisfaction caused by using these devices are shown in fig.2. It means the operation of washing machine and clothes dryer during the sleeping time will annoy the habitants due to the noise, and the dish washer should have cleaned the tableware and be off during the lunch and dinner time.

\section{Scheduling Optimization Algorithm}

In this research, we use Cooperative Particle Swarm Optimization (CPSO), which is based on the standard Particle Swarm Optimization (PSO), to search for the near-optimal scheduling and operation for each controllable devices in a

smart home, because of its straightforward implementation and demonstrated ability of optimization. 


\subsection{Standard Particle Swarm Optimization}

Standard Particle Swarm Optimization is derived from simulating social behavior as a stylized representation of the movement of organisms in a bird flock or fish school, which is originally proposed and developed by $[14,15]$. It is a metaheuristic algorithm that has been turned out to be powerful to solve complex non-linear and non-convex optimization problems [16]. Moreover, it has several other advantages, such as fewer parameters to adjust, and easier to escape from local optimal solutions.

In PSO, a population of candidate solutions, here dubbed particles that include position vector $\mathbf{x}$ and velocity vector $\mathbf{v}$, is randomly generated around the search-space initially. After that they are iteratively updated to simulate the movement around the search-space according to mathematical formulae over the particles' position and velocity, as expressed below:

$$
\begin{gathered}
\mathbf{v}_{i}^{k+1}=w \cdot \mathbf{v}_{i}^{k}+c_{1} \cdot \operatorname{rand}() \cdot\left(\mathbf{p}_{\mathbf{b e s t}}{ }_{i}^{k}-\mathbf{x}_{i}^{k}\right)+c_{2} \cdot \operatorname{rand}() \cdot\left(\mathbf{g}_{\text {best }}{ }^{k}-\mathbf{x}_{i}^{k}\right) \\
\mathbf{x}_{i}^{k+1}=\mathbf{x}_{i}^{k}+\mathbf{v}_{i}^{k+1}
\end{gathered}
$$

where $w$ is inertia weight, $c_{1}$ and $c_{2}$ are acceleration constants, $\operatorname{rand}()$ generates random value between 0 and $1, i$ is the particle index, $k$ is the iteration index,

$\mathbf{p}_{\text {best } i}^{k}$ is the local best position, and $\mathbf{g}_{\mathbf{b e s t}}{ }^{k}$ is global best position. For Equation 11, the first part expresses particle's inertia of previous action, the second part reflects particle's cognition that stimulates the particle to diminish errors, and the last part is called social part, which indicates the information sharing and cooperation among particles.

\subsection{Cooperative Particle Swarm Operation}

In this work, the problem involves multiple households, and in each of them contains multiple controllable appliances. Therefore, if it employs the standard PSO, a full dimensional vector should be constructed for each particle. This will cause the "two steps forward, one step back" problem [17], which can make the convergence very hard. In order to solve this problem that involves a large number of decision variables, we adopt and develop the CPSO proposed in [17]. The original method utilizes a divide-and-conquer approach. The vector to be optimized is divided into several components. Each swarm attempts to optimize only one of the components. The fitness of a particle belonging to one of the swarm is calculated by concatenating it with the present global best particles of the other swarms. In our study, we make trade-off between the swarm number and the particle vector dimension of each swarm.

In detail, nine swarms are designed for each smart home, of which four swarms optimize the space heater power, four swarms optimize the water heater power, and one swarm optimizes the starting time of the three time-shiftable devices, as shown in fig.3. Hence, each particle of the space heater swarm has 6 dimensions instead of only one dimension, and each dimension expresses the heating 
power for one hour. It's the same setting for water heater swarms. For the timeshiftable device swarm, each particle has 3 dimensions indicating the starting time of the three devices. As presented in subsection 2.1, the objective function of each household is to minimize the aggregation of the three sub-objectives: dissatisfaction, cost, and variance. The dissatisfaction and the cost of each home can be evaluated by its home agent after it has received the power data of powershiftable devices and the starting time data of time-shiftable devices, while the variance can be calculated only after all home agents of the district have sent their individual power scheduling data to the grid agent. Then a fitness is evaluated by summing these three parts up with different weights.

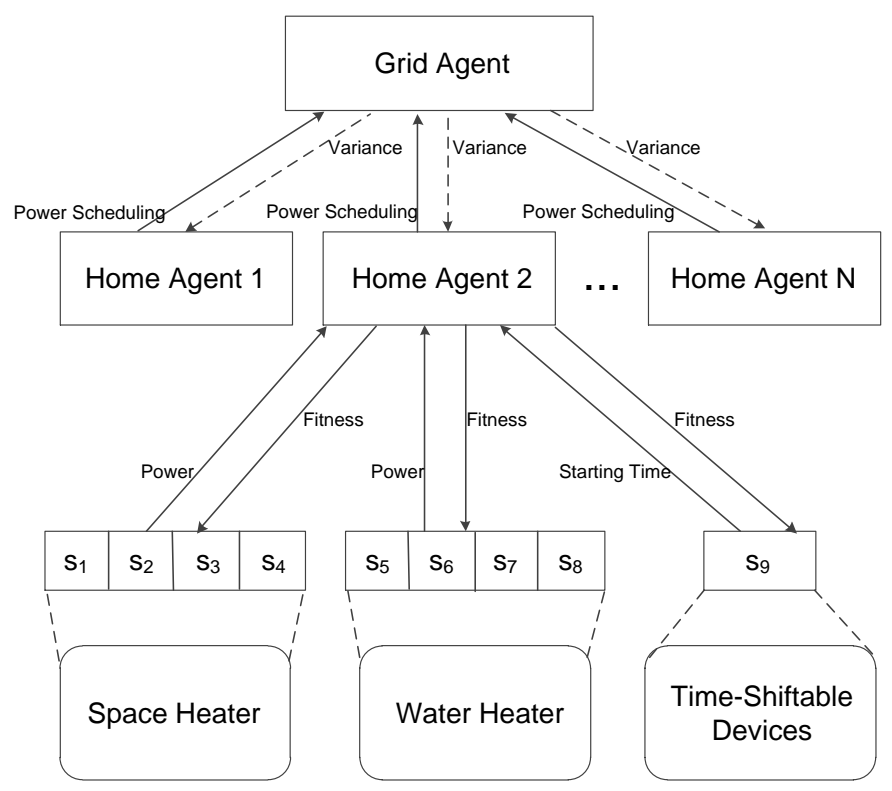

Fig. 3. CPSO Configuration and Operation

In addition, in our scheduling and operation optimization problem, there exists a risk of stagnation. This is caused by dividing one day's operation of power-shiftable devices into several sequential parts, and each part is optimized by a swarm. Although these swarms need to cooperate to find a near-optimal operation solution for one day, they work successively according to the time order. Consequently, the optimizing result of the former swarm will affect the fitness function of the latter one. Note that generally particles in a swarm tend to fly to the global best position, so if the fitness function changes a lot after a number of iterations, the algorithm will be stagnated at a wrong place. 
In order to solve this stagnation problem, we develop the original CPSO algorithm with particle reinitialization. The novel algorithm is called CPSO-R. In this algorithm, after a certain number of iterations the position and velocity of all particles will be reinitialized, but the global best position will be recorded. Based on this method, the stochastic initialization can easily make the algorithm jump out from the stagnation, because new random particles have the ability to explore the whole search-space.

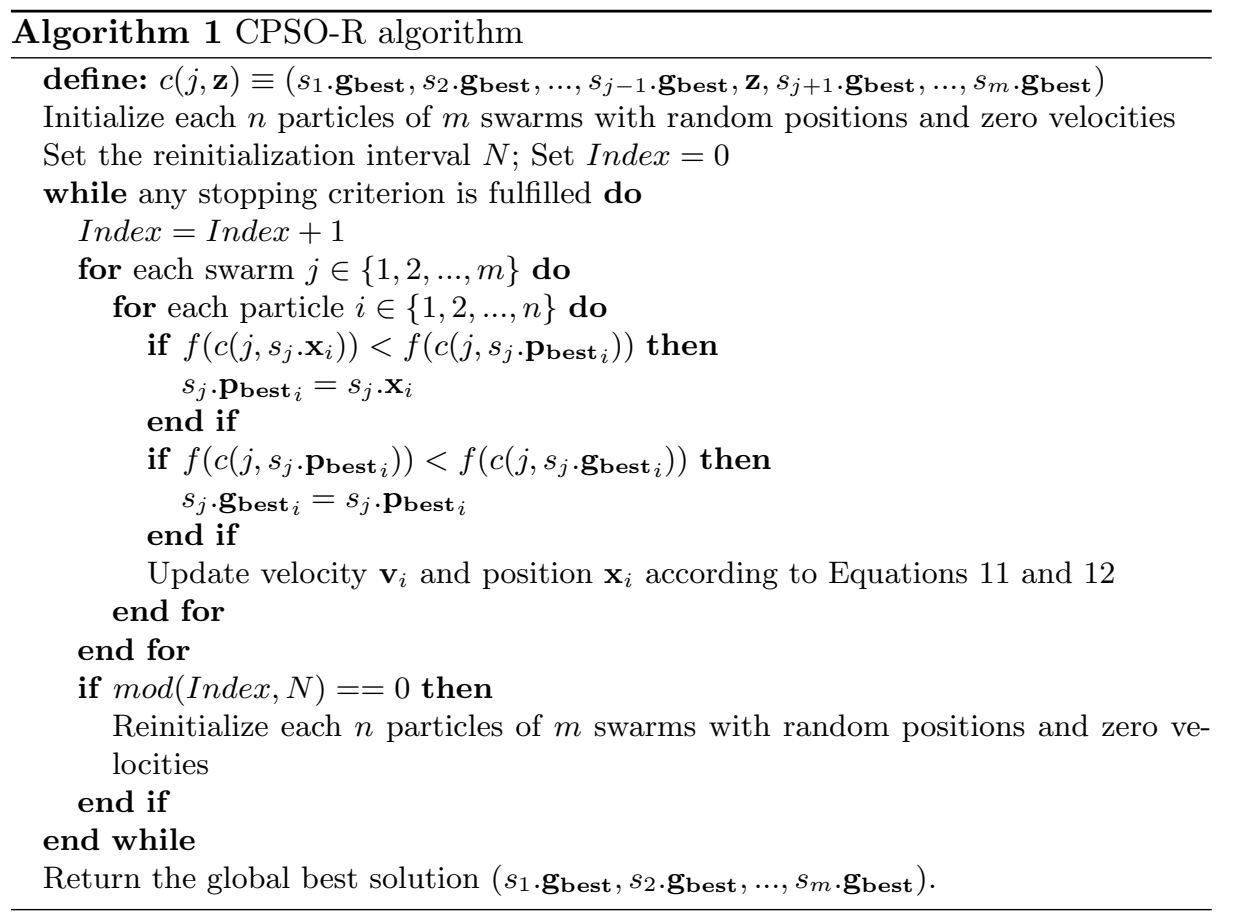

\section{Experimentation}

In this section, we show experimental results and provide analyses to demonstrate the performance of the presented algorithm. Before conducting the experiments, the parameters are set as: in CPSO-R, $w=0.72, c_{1}=1.49$, and $c_{2}=1.49$ [18]; in mathematical models of smart home, $\alpha=10^{-8}$, $\beta=10^{-3}, \epsilon=10^{-5}, \zeta=2, \theta=10^{-5}, \eta=5, R=21^{\circ} \mathrm{C} / \mathrm{kW}$, $C=0.125 \mathrm{kWh} /{ }^{\circ} \mathrm{C}, C_{\text {water }}=0.001167 \mathrm{kWh} / \mathrm{L} \cdot{ }^{\circ} \mathrm{C}, V_{\text {total }}=60 \mathrm{~L}, P_{\text {sh }}(t) \in$ $[0,2] k W, P_{w h}(t) \in[0,1.2] k W$, Washing Machine:\{2hour, $\left.1.4 k W\right\}$, Clothes Dryer: $\{1$ hour, $1.3 \mathrm{~kW}\}$, and Dish Washer: $\{3$ hour, $1.7 \mathrm{~kW}\}$. The time-varying electricity price and one day's ambient temperature are shown in fig.4 and fig.5. In order to show the impacts of demand response as well as coordinated actions 
of neighbouring smart homes in a district to avoid peak rebounds, three case studies are simulated and compared. In each simulation, five smart homes with the same settings in a district are taken into account and occupants are assumed at home except for $8: 00 \sim 12: 00$ and $14: 00 \sim 18: 00$ during which time they are assumed to be out for working.

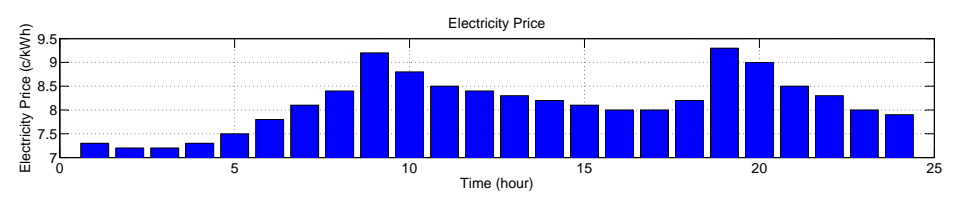

Fig. 4. Time-Varying Price [9]

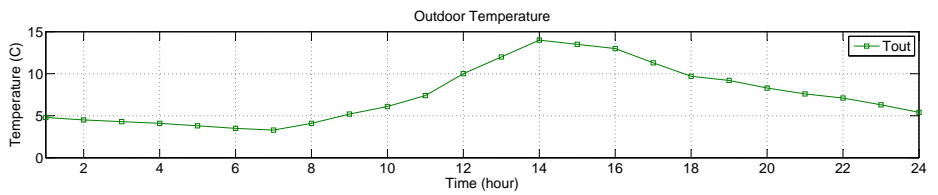

Fig. 5. Outdoor Temperature of One Day

Fig.6 shows the experimental results of the basic case. In this case, demand response and coordination are not considered and the algorithm is only used to control the space heater and the water heater, so there is no intelligent scheduling and operation for controllable appliances. When people turn them on, they work immediately and maximize people's comfort. Fig.6(c) shows that all the three time-shiftable devices of the five households are used after occupants return home in the evening. This not only causes peak loads on the main grid, as can be seen in fig.6(a), but also costs more money for the electricity prices during these periods are higher. Fig.6(b) and fig.6(d) show that the mean indoor temperature and the mean hot water temperature of the 5 families reach the desired degrees when people are at home.

In the second case, demand response is taken into account without coordination among different homes. Therefore, each individual home try to maximize its habitants' comfort as well as minimize the electrical bill. The performance of the space heater and the water heater is the same as in case 1. Moreover, from fig.7(b) we can see that time-shiftable devices are deferred to work during low price periods: dish washers are set to work during the middle of the night; while washing machines and clothes dryers are set to work during the afternoon, because they can annoy people if they work during the middle of the night. How- 


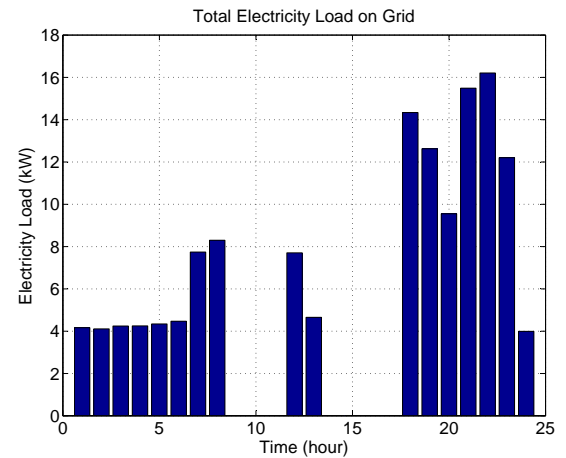

(a)

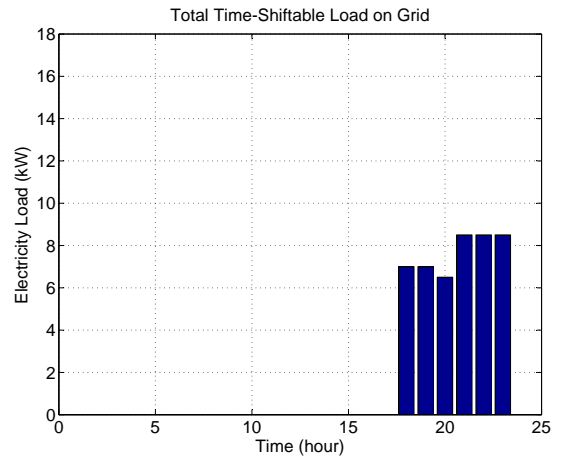

(c)

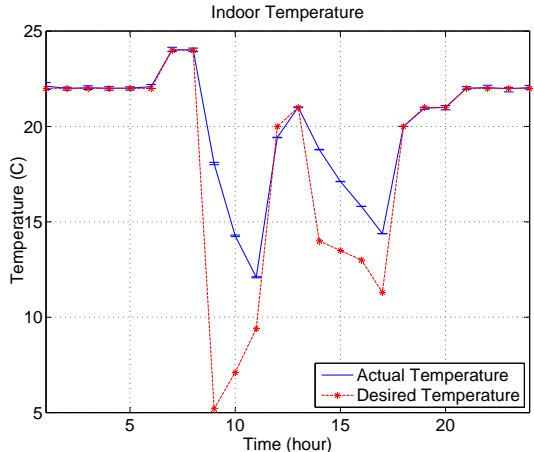

(b)

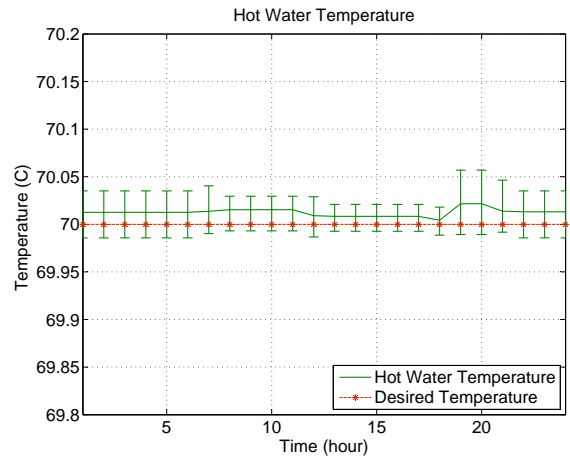

(d)

Fig. 6. Experimental Results of Case 1

ever, peak rebounds happen during the lowest price periods when dish washers of all homes work, as shown in fig. 7(a).

In order to solve the peak rebounds and make trade-off between electrical budget and comfort, all homes in the district are assumed to be able to coordinate by aggregating their electricity information on the main grid, and a 2-degree of indoor temperature and a 5-degree of hot water temperature from the desired temperatures are assumed to be tolerated for people. The experimental results of the case 3 are shown in fig.8. From fig.8(a), we can see that the variance of total load on the main grid is minimized, and peak loads and peak rebounds are avoided. Fig.8(b-d) show that by employing our proposed method, powershiftable devices and time-shiftable devices can work properly to guarantee their service quality. The comparison of the three cases is listed in tab.1, and we can find that with demand response and coordination our method can both save money and balance loads on the grid. 


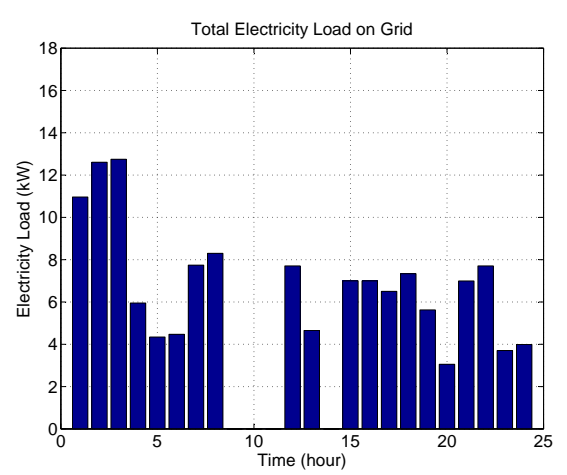

(a)

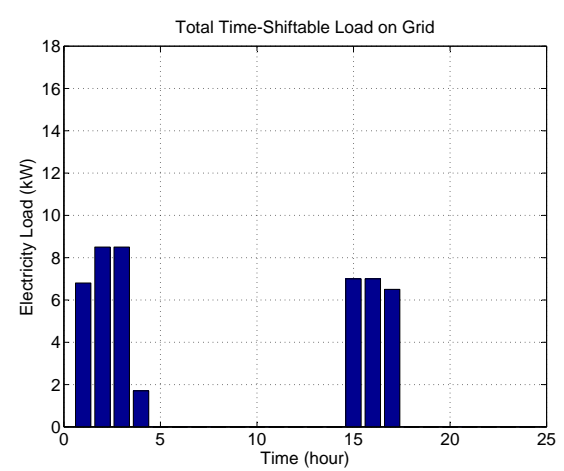

(b)

Fig. 7. Experimental Results of Case 2

Table 1. Comparison of The Three Cases

\begin{tabular}{lccc}
\hline & $\begin{array}{c}\text { mean cost } \\
\text { (cent euro) }\end{array}$ & $\begin{array}{c}\text { mean power } \\
(\mathrm{kW})\end{array}$ & $\begin{array}{c}\text { std. } \\
\text { (power on grid) }\end{array}$ \\
\hline Case 1 & 228.1 & 5.764 & 5.293 \\
Case 2 & 219.6 & 5.764 & 3.615 \\
Case 3 & 213.5 & 5.465 & 0.469 \\
\hline
\end{tabular}

\section{Conclusion}

This paper advocated the use of a metaheuristic algorithm based on cooperative particle swarm optimization to optimize scheduling and operation of timeshiftable and power-shiftable devices in a set of smart homes of a district. This method takes advantage of demand response and coordination of neighbouring homes to not only guarantee user comfort and reduce electrical bill of individual home but also avoid peak loads and peak rebounds on the main grid. The performance of the proposed algorithm was demonstrated by conducting and comparing three case study simulations. The experimental results indicate that selfish operation and optimization of individual home will make peak rebounds happen, which may damage the power grid, cause unforeseen disasters, and do harm to the global profit, while a coordinated management of a set of smart homes can get rid of this negative situation and increase the benefits bringing from demand response. In future work, the multi-agent based technique will be studied, and proactive and reactive agent properties will be capitalized on to construct a more intelligent system.

\section{References}

1. Ma, S., Chen, X., Song, G., Wang, J., Sun, L., Yan, J.: The converged service oriented architecture in smart home service. In: Cyber-Enabled Distributed Com- 


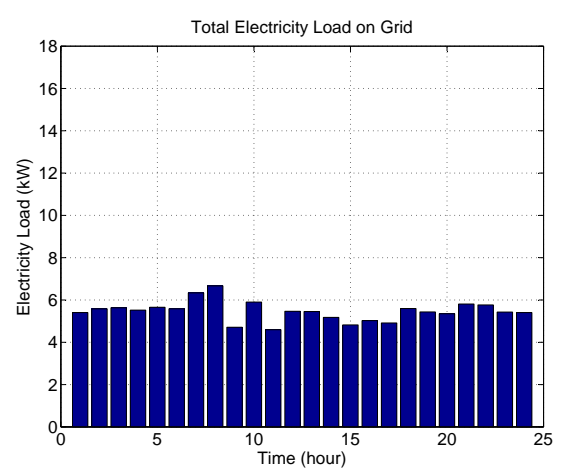

(a)

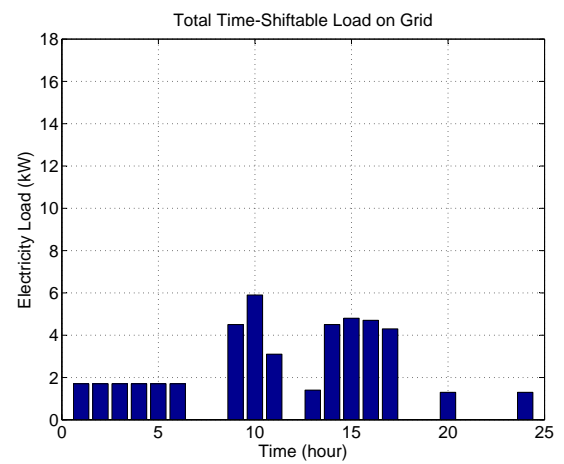

(c)

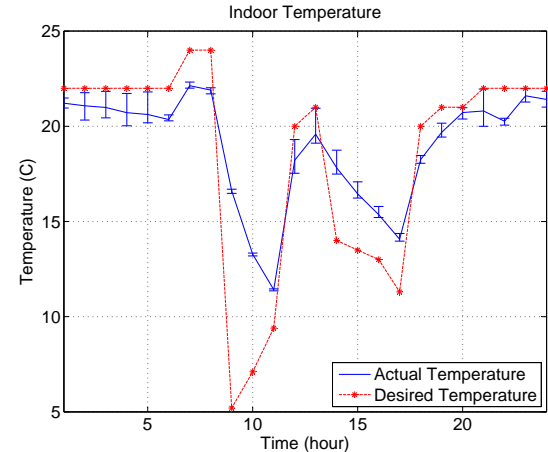

(b)

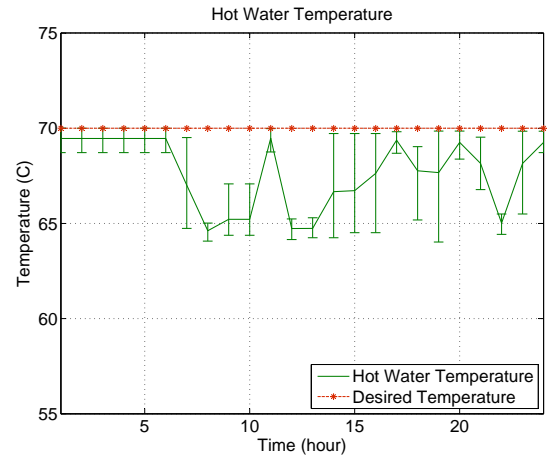

(d)

Fig. 8. Experimental Results of Case 3

puting and Knowledge Discovery (CyberC), 2012 International Conference on. (Oct 2012) 237-240

2. Ricquebourg, V., Menga, D., Durand, D., Marhic, B., Delahoche, L., Loge, C.: The smart home concept : our immediate future. In: E-Learning in Industrial Electronics, 2006 1ST IEEE International Conference on. (Dec 2006) 23-28

3. DoE: U.S. Department of Energy / Smart Grid. http://energy.gov/oe/services/technology-development/smart-grid (2015)

4. Siano, P.: Demand response and smart gridsa survey. Renewable and Sustainable Energy Reviews 30(0) (2014) $461-478$

5. Chen, Z., Wu, L., Fu, Y.: Real-time price-based demand response management for residential appliances via stochastic optimization and robust optimization. Smart Grid, IEEE Transactions on 3(4) (Dec 2012) 1822-1831

6. Chen, X., Wei, T., Hu, S.: Uncertainty-aware household appliance scheduling considering dynamic electricity pricing in smart home. Smart Grid, IEEE Transactions on 4(2) (June 2013) 932-941

7. Pedrasa, M., Spooner, T., MacGill, I.: Coordinated scheduling of residential distributed energy resources to optimize smart home energy services. Smart Grid, 
IEEE Transactions on 1(2) (Sept 2010) 134-143

8. Li, Y., Ng, B.L., Trayer, M., Liu, L.: Automated residential demand response: Algorithmic implications of pricing models. Smart Grid, IEEE Transactions on 3(4) (Dec 2012) 1712-1721

9. Safdarian, A., Fotuhi-Firuzabad, M., Lehtonen, M.: A distributed algorithm for managing residential demand response in smart grids. Industrial Informatics, IEEE Transactions on 10(4) (Nov 2014) 2385-2393

10. Kahrobaee, S., Rajabzadeh, R., Soh, L.K., Asgarpoor, S.: A multiagent modeling and investigation of smart homes with power generation, storage, and trading features. Smart Grid, IEEE Transactions on 4(2) (June 2013) 659-668

11. Mohsenian-Rad, A.H., Leon-Garcia, A.: Optimal residential load control with price prediction in real-time electricity pricing environments. Smart Grid, IEEE Transactions on 1(2) (Sept 2010) 120-133

12. Atzeni, I., Ordonez, L., Scutari, G., Palomar, D., Fonollosa, J.: Demand-side management via distributed energy generation and storage optimization. Smart Grid, IEEE Transactions on 4(2) (June 2013) 866-876

13. ASHRAE: ASHRAE Handbook: Fundamentals. American Society of Heating, Refrigerating, and Air-Conditioning Engineers (2005)

14. Kennedy, J., Eberhart, R.: Particle swarm optimization. In: Neural Networks, 1995. Proceedings., IEEE International Conference on. Volume 4. (Nov 1995) 1942-1948 vol.4

15. Shi, Y., Eberhart, R.: A modified particle swarm optimizer. In: Evolutionary Computation Proceedings, 1998. IEEE World Congress on Computational Intelligence., The 1998 IEEE International Conference on. (May 1998) 69-73

16. Lin, F.J., Teng, L.T., Lin, J.W., Chen, S.Y.: Recurrent functional-link-based fuzzy-neural-network-controlled induction-generator system using improved particle swarm optimization. Industrial Electronics, IEEE Transactions on 56(5) (May 2009) 1557-1577

17. van den Bergh, F., Engelbrecht, A.: A cooperative approach to particle swarm optimization. Evolutionary Computation, IEEE Transactions on 8(3) (June 2004) 225-239

18. Eberhart, R., Shi, Y.: Comparing inertia weights and constriction factors in particle swarm optimization. In: Evolutionary Computation, 2000. Proceedings of the 2000 Congress on. Volume 1. (2000) 84-88 vol.1 